\title{
Application of Nylon6/Polypyrrole core-shell nanofibre mat as solid-phase extraction adsorbent for the determination of atrazine in environmental water samples
}

Bi-Yi Yang, Fei-Fei Qi, Xiao-Qing Li, Jing-Jing Liu, Fei Rong and Qian Xu

\section{Supplemental material}

\subsection{Optimisation of SPE conditions}

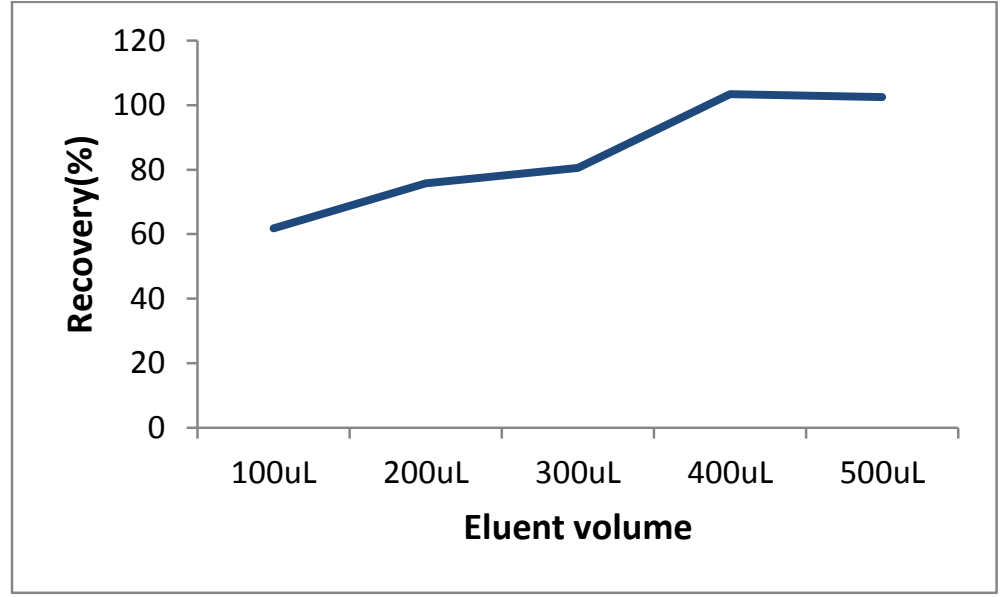

Figure 1 Effect of amount of adsorbent on recoveries of atrazine. Conditions: amount of adsorbent, $3.0 \mathrm{mg}$; volume of the sample, $10 \mathrm{~mL}$; concentration of sample solution, $5 \mathrm{ng} / \mathrm{mL}$; concentration of $\mathrm{NaCl}, 10 \%(\mathrm{~W} / \mathrm{V})$; $\mathrm{pH}$ of the sample, 7 ; flow rate of the sample, $2.5 \mathrm{~mL} / \mathrm{min}$.

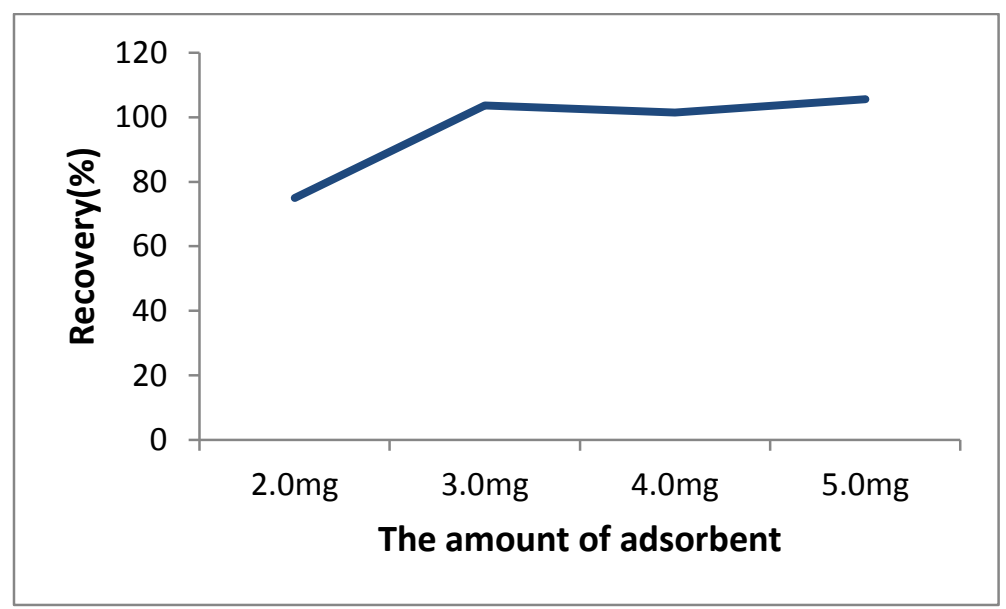

Figure 2 Effect of amount of adsorbent on recoveries of atrazine. Conditions: volume of the sample, $10 \mathrm{~mL}$; concentration of sample solution, $5 \mathrm{ng} / \mathrm{mL}$; concentration of $\mathrm{NaCl}, 10 \%(\mathrm{~W} / \mathrm{V})$; $\mathrm{pH}$ of the sample, 7; flow rate of the sample, $2.5 \mathrm{~mL} / \mathrm{min}$; elution, $400 \mu \mathrm{L}$ acetonitrile. 


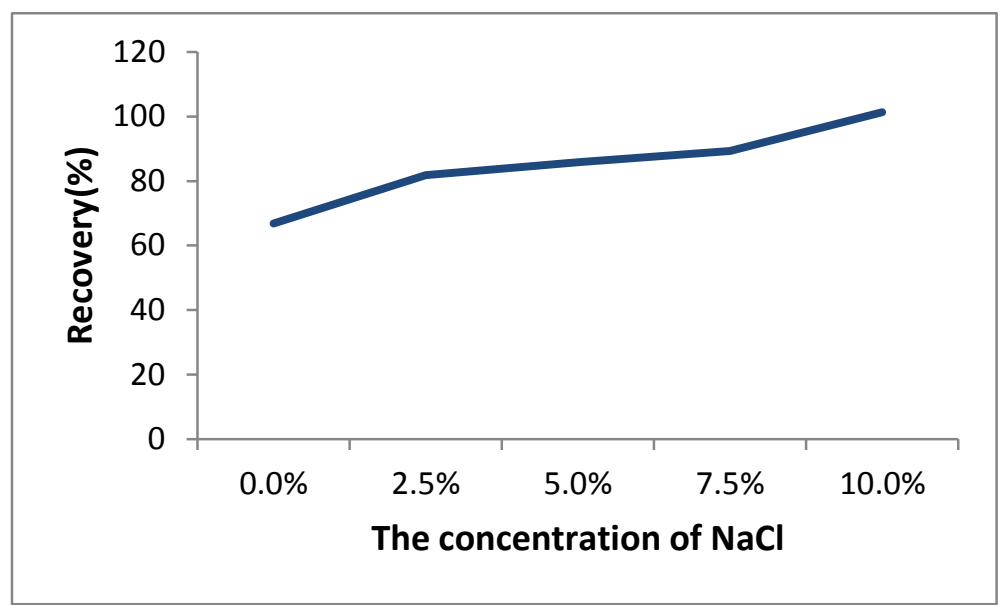

Figure 3 Effect of concentration of $\mathrm{NaCl}$ on recoveries of atrazine. Conditions: amount of adsorbent, $3.0 \mathrm{mg}$; volume of the sample, $10 \mathrm{~mL}$; concentration of sample solution, $5 \mathrm{ng} / \mathrm{mL} ; \mathrm{pH}$ of the sample, 7; flow rate of the sample, $2.5 \mathrm{~mL} / \mathrm{min}$; elution, $400 \mu \mathrm{L}$ acetonitrile.

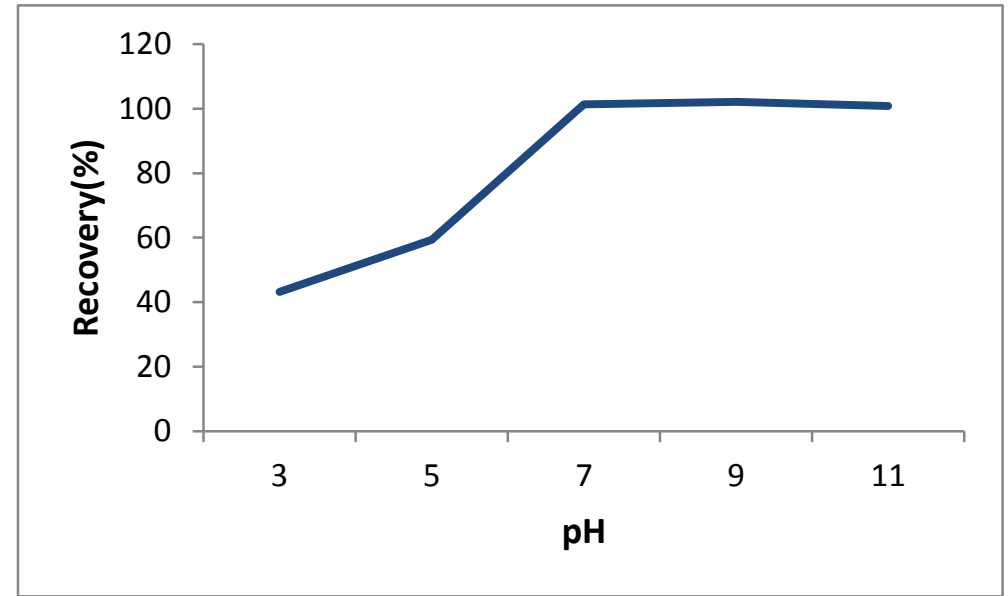

Figure 4 Effect of $\mathrm{pH}$ on recoveries of atrazine. Conditions: amount of adsorbent, 3.0mg; volume of the sample, $10 \mathrm{~mL}$; concentration of sample solution, $5 \mathrm{ng} / \mathrm{mL}$; concentration of $\mathrm{NaCl}, 10 \%$ (W/V);flow rate of the sample, $2.5 \mathrm{~mL} / \mathrm{min}$; elution, $400 \mu \mathrm{L}$ acetonitrile. 